\title{
MENGGALI POTENSI ENERGI LISTRIK "ENERGI BARU TERBARUKAN" BERSUMBER DARI PRODUKSI KELAPA SAWIT BIOMASSA DI ACEH TAMIANG
}

\author{
Rahmad Purnama $^{1}$, Hefri Yuliadi ${ }^{2}$, Boas Aritonang ${ }^{3}$, Mhd Fitra Zambak ${ }^{4}$, Feri Kurniawan ${ }^{5}$ \\ ${ }^{1}$ Ekonomi PembangunanFakultas Ekonomi Universitas Terbuka, ${ }^{2,3,4}$ Magister Teknik Elektro \\ Universitas Muhamadiyah Sumatera Utara, ${ }^{5}$ SMK Negeri 2 Karang Baru \\ 1rahmad.mk@gmail.com, ${ }^{2}$ hefri.yuliadi@yahoo.com, ${ }^{3}$ boasart12345@gmail.com, \\ 4mhdfitra@umsu.ac.id, ${ }^{5}$ ferismk2@gmail.com
}

\begin{abstract}
Listrik merupakan kebutuhan primer, sehingga Pemerintah Pusat didalam hal ini dibawah menteri ESDM bertanggung jawab atas pemenuhan kebutuhan ini dengan cara mengeluarkan Undang undang tentang penyediaan energi listrik seperti yang tertuang dalam Undang-Undang No. 30 tahun 2009 tentang ketenagalistrikan. Pemda baik Kabupaten dan Kabupaten/Kota Mempunyai peran membuat kebijakan berdasarkan kajian potensi energi listrik yang dimiliki gunakan untuk menjaga penyediaan energi listrik dari sekarang. Penelitian ini mengkaji tentang potensi pembangkit energi listrik yang bersumber dari energi terbarukan Biomass di Kabupaten Aceh Tamiang. Tujuan untuk mendapatkan gambaran potensi energi baru terbarukan yang ada di Kabupaten Aceh Tamiang dan dapat menentukan kebijakan energi listrik untuk pembangunan penyediaan energi listrik yang tepat dan efektif. metode penelitian adalah penelitian kuantitatif penelitian ini menggunakan data sekunder. Produksi sawit pada tahun 2013 mencapai 6.735.795,45 ton denganjumlah lahan 393.990 ha Setiap hektar kebun kelapa sawit menghasilkan 17 ton tandan buah segar dan setiap Hektar lahan ditanami 148 pohon sawit dengan demikian untuk setiap pohon kelapa sawit menghasilan $115 \mathrm{~kg} / \mathrm{tahun}$. Sehingga dengan jumlah produksi yang bersar tersebut maka didapatkan energi listrik yang terbangkit dari potensi limbah produksi kelapa sawit adalah 1.573 MWh. Potensi ini dapat membantu pemenuhan energi nasional 35 Ribu MWh.
\end{abstract}

\section{Kata Kunci : Listrik, ESDM dan Kepala Sawit}

\section{Pendahuluan}

Pada era teknologi yang berkembang saat ini listrik merupakan kebutuhan primer, bagaimana tidak, semua peralatan masyarakat pada zaman saat ini sudah menggunakan peralatan listrik. Adapun peralatan kebutuhan rumah tangga harus terhubung dengan peralatan lisrik seperti penanak nasi listrik (Rice Cooker), Pemanas air ( Dispenser) alat penggiling bumbu dan masih banyak lagi. Peralatan Lisrik ini digunakan karena effesiensinya tinggi dan biaya operasional tergolong murah. Purnama (2015) menyatakan bahwa kebutuhan energi listrik akan meningkat seiring dengan pertumbuhan ekonomi. Hal ini dapat dilihat dari kegiatan ekomoni yang akan menghasilkan pertumbuhan ekonomi tersebut, dengan terjadi peningkatan tersebut juga akan meningkatnya kebutuhan konsumsi tidak hanya makanan juga konsumsi energi listrik [1].Pemerintah pusat didalam hal ini dibawah menteri ESDM terlah mengeluarkan Undang undang tentang penyediaan energi listrik seperti yang tertuang dalam Undang-Undang No. 30 tahun 2009 tentang ketenagalistrikan. Sedangkan Pemda Provinsi baik Kabupaten ataupun Kota Mempunyai peran penting sebagai pemegang kekuasan yang bertugas membuat kebijakan berdasarkan kajian potensi energi listrik yang dimiliki gunakan untuk menjaga penyediaan energi listrik dari sekarang.Pemerintah Pusat dalam hal ini Direktorat Sumber Daya Energi, Mineral dan Pertambangan dibawah naungan Badan 
Perencanaan Pembangunan Nasional (BAPPENAS) telah mengeluarkan Kebijakan Energi Nasional (KEN). Kebijakan Energi Nasional ini mengamanatkan serta metuntut pembangunan daerah agar dapat menkaji Potensi Energi yang dimiliki guna pembangunan berkelanjutan sehingga pemerintah ddapat dengan matang pembangunan berkelanjutan dapat terwujudAdapun penelitian ini mengkaji tentang potensi pembangkit energi listrik yang bersumber dari energi terbarukan Biomass di Kabupaten Aceh Tamiang kajian ini merupakan langkah awal untuk pertimbangan Pemerintah Daerah menentukan kebijakan mengenai potensi energi baru terbarukan yang dimiliki. Sehingga dengan pembahasan ini pemerintah mendapatkan gambaran potensi energi baru terbarukan yang ada di Kabupaten Aceh Tamiang dan dapat menentukan kebijakan energi listrik untuk pembangunan penyediaan energi listrik yang tepat dan efektif.

\section{Tinjuan Pustaka}

\subsection{Teori Perencanaan Ketenagalistrikan Nasional.}

Regulasi tentang ketenagalistrikan pertama adalah Undang - Undang Nomor 15 Tahun 1985 tentang ketenagalistrikan, Peraturan Pemerintah Nomor 10 Tahun 1989 tentang Penyediaan dan Pemanfaatan Tenaga Listrik sebagaimana telah dua kali di Amandemen terakhir dengan Peraturan Pemerintah Nomor 26 Tahun 2006, maka seluruh pelaku usaha penyediaan tenaga listrik yang memiliki wilayah usaha wajib membuat Rencana Umum Penyediaan Tenaga Listrik (RUPTL) dengan mengacu kepada RUKN [2].

Dalam Riset sebelumnya sudah yang membuat gambaran tentang skema tentang perumusan RUPTL [3] , adapun yang menjadi skema perumusan dapat di lihat pada gambar 1

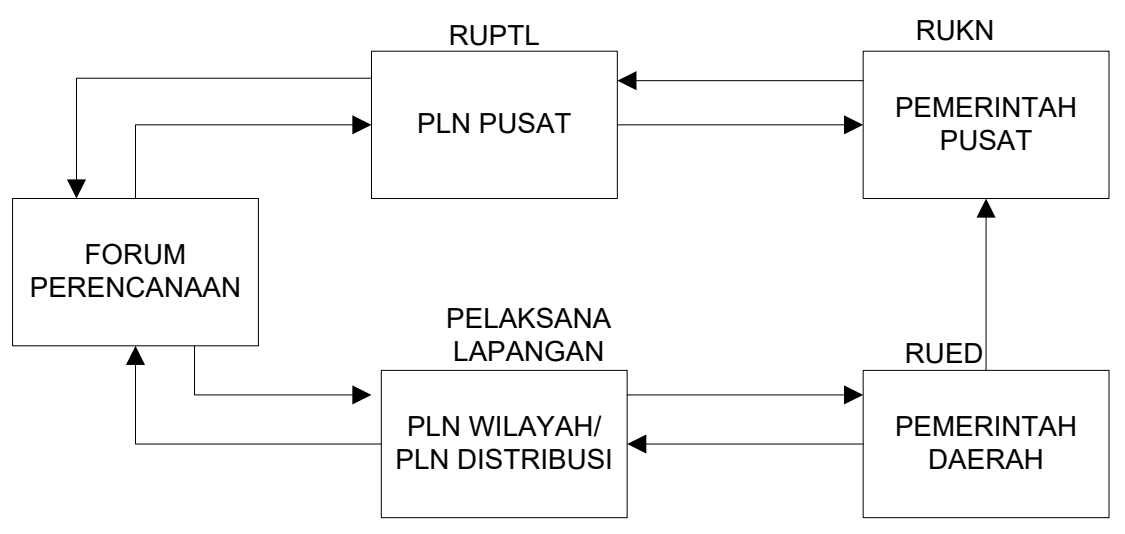

Gambar 1. Skema Proses Perumusan RUPTL

Proses perencanaan sistem ketenagalistrikan dijelaskan Novitasari (2012) dalam keputusan Menteri Energi dan Sumber Daya Mineral tentang Pedoman Penyusunan Rencana Umum Ketenagalistrikan. Untuk menyusun Rencana Umum Ketenagalistrikan Nasional (RUKN) dan rencana Umum Ketenagalistrikan Daerah (RUKD) harus mengikuti proses perencanaan.

Dalam keputusan menteri tersebut juga dijelaskan tentang asas Perencanaan ketenagalistrikan dimana asas perencanaan ketenagalistrikan tersebut berpedoman pada asas biaya terendah (least cost), Potensi yang dimiliki oleh daerah tersebut sehingga penyediaan tenaga listrik, pemakaian tenaga listrik yang kesemuanya dapat dilakukan secara terintegrasi. 


\subsection{Faktor yang Mempengaruhi Kebutuhan Energi Listrik.}

Energi listrik saat ini sudah menjadi kebutuhan primer dalam kehidupan masyarakat, karena menjadi kebutuhan primer maka kebutuhan konsumsi energi listrik ini akan mengalami peningkatan. Peningkatannya akan terus berkembang dengan bentuk grafik naik dari waktu ke waktu. beberapa faktor yang mempengaruhi kebutuhan energi listrik, Pertumbuhan Penduduk [4], Pertumbuhan Ekonomi, Faktor-faktor lain Seperti dipengaruhi oleh jumlah anggota dalam rumah tangga dan rencana pembangunan daerah setempat.

\subsection{Model dan Pendekatan Perencanaan Energi.}

Perencanaan energi terdapat beberapa model pendekatan. Berdasarkan keputusan menteri ESDM juga menyebutkan beberapa model pendekatan perencanaan energi yang biasa digunakan yaitu pendekatan end-use, ekonometrika, proses, dan trend [5]

\subsection{Teori Energi Baru terbarukan (Biomass)}

Biomassa merupakan salah satu sumber energi yang telah digunakan sejak dari jaman dahulu kala. Biomassa adalah semua benda organik (misal: kayu, tanaman pangan, limbah hewan \& manusia) dan bisa digunakan sebagai sumber energi untuk memasak, memanaskan dan pembangkit listrik. Sumber energi ini bersifat terbarukan karena pohon dan tanaman pangan akan selalu tumbuh dan akan selalu ada limbah tanaman [6][7]. Limbah tanaman sawit merupakan salah satu limbah tananam hasil pemanfaatan sawit yang dijadikan VCO (Virgin Couconout Oil). Limbah ini banyak ditemukan pada PKS (Pabrik Kelapa Sawit). Adapun limbah yang dihasilkan dari pembuatan VCO di PKS berupa 0,6 \% cangkang, $23 \%$ bungkil kosong dan $12 \%$ serabut dari produksi 1 ton sawit segar (Kusuma, 2010).

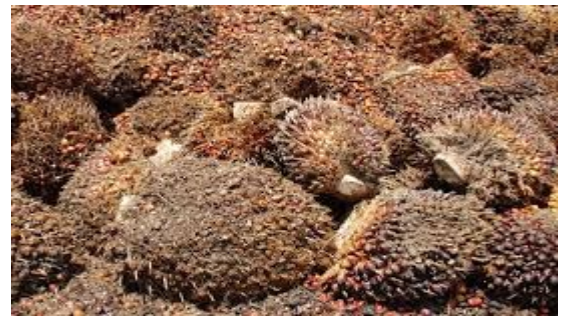

Gambar 2. Buah Sawit Segar.

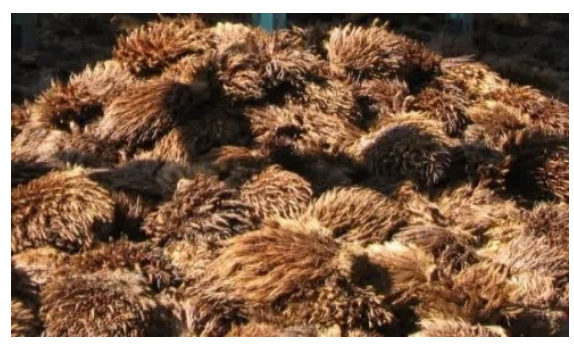

Gambar 4. Tandan Kosong

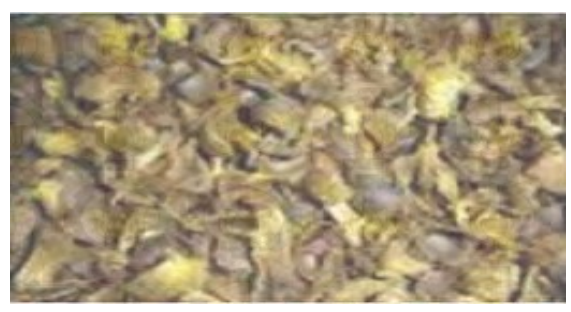

Gambar 3. Cangkang Sawit.

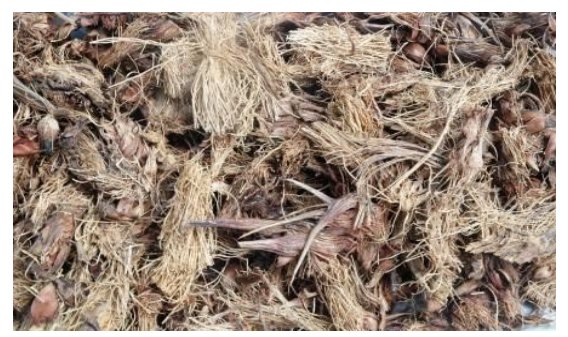

Gambar 5. Serat Sawit.

Tabel 1. Kalori dari Kelapa Sawit

\begin{tabular}{|c|c|c|}
\hline No & Jenis Limbah & Kandungan Kalori \\
\hline 1 & Serat & $3500-4100 \mathrm{kkal} \mathrm{kg}$ \\
\hline 2 & Cangkag & $2637-3998 \mathrm{kkal} \mathrm{kg}$ \\
\hline 3 & Tandan Buah Kosong & $4492 \mathrm{kkal} \mathrm{kg}$ \\
\hline
\end{tabular}




\section{Metode Penelitian}

\subsection{Metode penelitan}

Adapun metode penelitian adalah penelitian kuantitatif penelitian ini menggunakan data sekunder yang diperoleh dari beberapa Dinas dan Instansi terkait yang ada diKabupaten Aceh Tamiang dan dari data kajian sebelumnya. Adapun data yang dibutuhkan untuk menghitung potensi energi terbarukan dari biomassa adalah Jumlah produksi sawit (Biomass), produksi yang ada di Kabupaten Aceh Tamiang.

\subsection{Alur Penelitia}

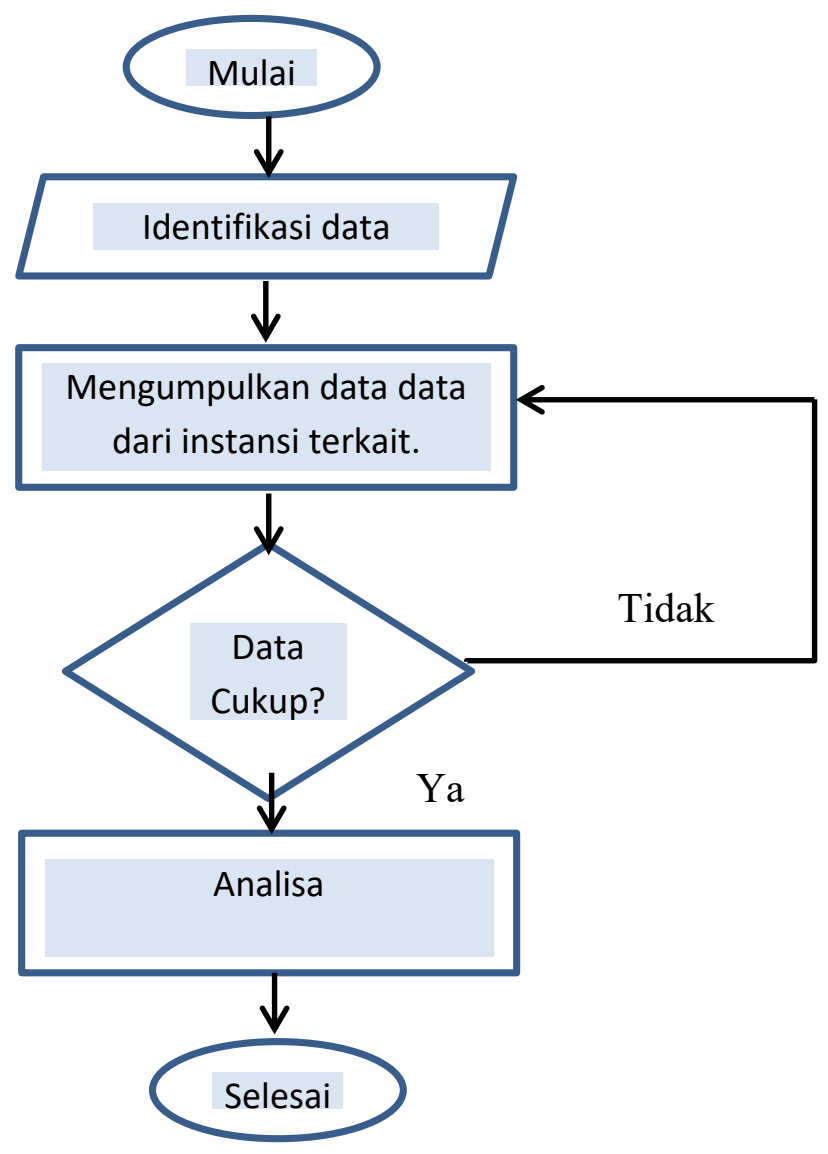

Gambar 6. Alur Penelitian

\section{Hasil dan Analisa}

\subsection{Data Potensi Biomassa.}

Aceh Tamiang Memiliki Potensi biomassa yang besar karena sebahagian besar wilayahnya dikelilingi dengan perkebunan sawit. Sehingga luasnya perekebunan kelapa sawit tersbut yang memproduksi kelapa sawit menyisakan limbah dari produksi sawit limbah sawit yang cukup besar pula. Produksi sawit pada tahun 2013 mencapai 6.735.795,45 ton. Jumlah ini terus mengalami Peningkatan dikarenakan pada tahun 2008 -2010 merupakan masa penanaman perkebunan kelapa sawit. Hasil dari produksi kelapa sawit ini harus dilakukan studi lebih lanjut mengenai Teknologi yang dapat dipergunakan untuk mengkonversi menjadi listrik [8][9][10][11][12][13][14][15][16][17] 


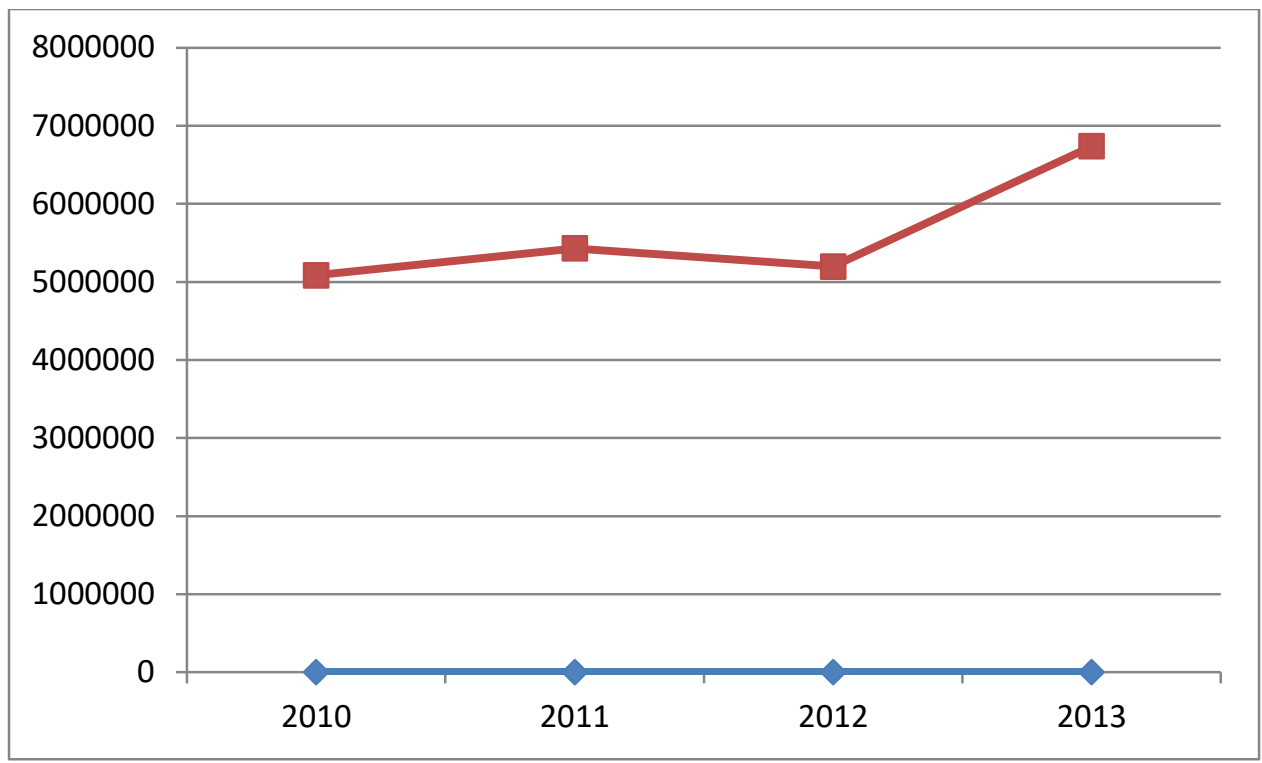

Grafik 7. Jumlah Produksi Sawit Aceh Tamiang

\subsection{Potensi Biomassa.}

Produksi kelapa sawit di Kabupaten Aceh Tamiang pada tahun 2013 tergolong cukup tinggi yakni mencapai $6.735 .795,45$ ton dari jumlah lahan $\mathbf{3 9 3 . 9 9 0}$ ha Setiap hektar kebun kelapa sawit menghasilkan 17 ton tandan buah segar dan setiap Hektar lahan ditanami 148 pohon sawit dengan demikian untuk setiap pohon kelapa sawit menghasilan $115 \mathrm{~kg} / \mathrm{tahun}$. Energi Biomassa limbah kelapa sawit merupakan salah satu sumber energi terbarukan yang dapat menjawab kebutuhan energi alternatif. Limbah kelapa sawit ini memiliki kandungan kalori yang cukup tinggi. Untuk setiap 1 ton pengolahan tandan buah segar (TBS) akan dihasilkan $120 \mathrm{~kg}$ serat, $230 \mathrm{~kg}$ bungkil kosong, $60 \mathrm{~kg}$ cangkang. Serat didapatkan dengan jalan mengepres buah yang terdiri dari sejumlah minyak dengan mesin screw press. Setelah itu, serat buah kelapa sawit akan terpisah dengan bijinya. Sebenarnya serat ini masih mengandung sedikit minyak. Kalori yang terkandung diserat ini sekitar 2637-4554 kkal/kg.Bagian luar biji yang dipisahkan dari inti dinamakan cangkang. Cangkang ini didapatkan dengan memecah biji buah kelapa sawit dengan alat pemecah. Cangkang ini mempunyai kalori yang tinggi sekitar 4105-4802 kkal/kg, sehingga dapat dikonversikan menjadi energi listrik. Tapi dalam penggunaannya cangkang ini hanya digunakan beberapa persen saja.Bungkil kosong atau disebut juga tandan kosong didapatkan dengan cara, proses tandan buah segar (TBS) yang dikelupas dengan menggunakan alat kupas (Thresher). Sehingga buah kelapa sawit mengelupas (keluar) dari tandan buah segar (TBS). Bungkil kosong ini presentase jumlahnya paling besar bila dibanding dengan limbah kelapa sawit lain dan mempunyai kalori yang tinggi sekitar $4492 \mathrm{kkal} / \mathrm{kg}$ sehingga juga dapat dikonversikan ke dalam bentuk energi yang lain misal energi panas.Dalam menganalisa potensi biomasa dari potensi limbah kelapa sawit maka dilakukan dengan cara menghitung per bagian yaitu Tandan Kosong(TanKos), Cangkang dan Serabut.

Analisa potensi biomassa dilakukan dengan tahap sebagai berikut :

- $\quad$ Produksi Sawit x 23\% (TanKos) = TanKos (kg/tahun).

- $\quad 6.735 .795,45$ ton $\mathrm{x} 0,23=1.549 .232 .954 \mathrm{~kg} / \mathrm{tahun}$.

- $\quad$ Produksi Sawit x 6\% (Cangkang) = Cangkang ( $\mathrm{kg} /$ tahun).

- $\quad 6.735 .795,45$ ton x $0,06=404.147 .727 \mathrm{~kg} / \mathrm{tahun}$.

- $\quad$ Produksi Sawit x 12\% (Serabut) = Serabut (kg/tahun).

- $\quad 6.735 .795,45$ ton $x 0,12=808.295 .454(\mathrm{~kg} /$ tahun$)$. 
Sedangkan kandungan kalori setiap bagian limbah sawit dari Tandan Kosong 4492 kkal, Cangkang $4100 \mathrm{kkal}$, dan Serabut 3998 kkal. Maka total dari kalori limbah kelapa sawit yang dihasilkan setiap tahunnya sebagai berikut :

- Jumlah Tandan Kosong x $4492=$ Total Kalori (Kkal. Kg.)

- $\quad 1.549 .232 .954$ x $4492=6.959 .154 .427 .122 \mathrm{Kkal} . \mathrm{Kg}$

- Jumlah Cangkang x $4100=$ Total Kalori (Kkal. Kg.)

- $\quad 404.147 .727$ x $4100=1.657 .005 .680 .700 \mathrm{Kkal} . \mathrm{Kg}$

- Jumlah Serabut x $4492=$ Total Kalori (Kkal. Kg.)

- $\quad$ 808.295.454 x $4492=3.231 .565 .225 .092 \mathrm{Kkal} . \mathrm{Kg}$.

Dilakukan konversi dari Kkal Menjadi watt dengan proses dirubah terlebih dahulu kedalam satuan joule dengan cara berikut, $1 \mathrm{Kkal}=1,163986$ watt. Sehingga pada proses perhitungan menggunakann

- $\quad 6.959 .154 .427 .122 \mathrm{KkaL} / \mathrm{kg}$ (TanKos) $\mathrm{x} 1,163986$ watt $=8.093 .489 .639 .588$ watt

- $\quad$ 1.657.005.680.700 KkaL/kg (Cangkang) x 1,163986 watt $=1.927 .095 .949 .648$ watt

- $\quad 3.231 .565 .225 .092 \mathrm{KkaL} / \mathrm{kg}$ (Serat) 1,163986 watt $=3.758 .307 .125 .217$ watt

Konversi mejadi Megawatt di bagi satu juta (1.000.000)

- $\quad$ 8.093.489.639.588 watt (Tandang Kosong) : $1.000 .000=8.093 .490$ MWatt

- $\quad 1.927 .095 .949 .648$ watt (Cangkang): $1.000 .000=1.927 .096 \mathrm{MWatt}$

- $\quad 3.758 .307 .125 .217$ watt (Serat) : $1.000 .000=3.758 .307$ MWatt.

Dengan demikian potensi biomasa yang berasal dari limbah kelapa sawit di Kabupaten Aceh Tamiang dapat menghasilkan energi listrik adalah dalam satuan $\mathrm{Mw}$ :

- $\quad$ TanKos (8.093.490 MWatt) + Cangkang (1.927.096 MWatt) + Serabut (3.758.307 MWatt.) $=13.778 .893$ MWatt.

- Jumlah 13.778.893 MW merupakan jumlah energi yang dihasilkan dalam kurun waktu satu tahun dari potensi energi baru terbarukan dari produksi kelapa sawit yang dimiliki oleh Kabupaten Aceh Tamiang. Namun Untuk menghitung energi yang terbangkit dalam satuan KWh maka Perlu dibagi dengan jumlah jam dalam satu tahun 8760 jam sehingga energi terbangkit adalah $13.778 .893 \mathrm{MW}: 8760$ Jam $=1.573 \mathrm{MWh}$

\section{Kesimpulan}

Poteni energi baru terbarukan yang bersumber dari biomassa yang bersumber dari limbah produksi kelapa sawit di Kabupaten Aceh Tamiang memiliki potensi yang sangat besar. Potensi ini bisa dimanfaatkan sebagai energi alternatif untuk memenuhi kebutuhan listrik untuk Kabupaten Aceh Tamiang. Energi listrik yang terbangkit dari potensi limbah produksi kelapa sawit adalah 1.573 MWh. Potensi ini dapat membantu pemenuhan energi nasional 35 Ribu MWh.

\section{Daftar Pustaka}

[1] Purnama Rahmad, 2015, Perkiraan Konsumsi Energi Listrik 2015 -2030 Dan Potens Pembangkit Listrik Energi Baru Terbarukan di Aceh Tamiang, Tesis, Program Pasca Sarjanah Fakultas Teknik Universitas Gajah Mada.

[2] Keputusan Menteri Energi Dan Sumber Daya Mineral Nomor : 2682 K/21/Mem/2008 Tentang Rencana Umum Ketenagalistrikan Nasional 2008 S.D. 2027.

[3] Fitrianto kurniawan dkk, 2006, Prakiraan Kebutuhan Energi Listrik Tahun 2006 - 2015 Pada Pt. Pln (Persero) Unit Pelayanan Jaringan (UPJ) Di Wilayah Kota Semarang 
Dengan Metode Gabungan, Makalah seminar tugas akhir, Jurusan Teknik Elektro Fakultas Teknik Universitas Diponegoro Semarang.

[4] Kusuma Indra Permata, 2010, Studi Pemanfaatan Biomassa Limbah Kelapa Sawit Sebagai Bahan Bakar Pembangkit Listrik Tenaga Uap di Kalimantan Selatan (Studi Kasus Kab Tanah Laut), , Persentasi,Departemen Tenik Listrik, Fakultas Teknologi Industri, Institut Teknologi Sepuluh November.

[5] Darmawan Arif, 2012, Proyeksi Permintaan Listrik Sektor Rumah Tangga Menggunakan end-Use ModeL (Studi Kasus Kota Yogyakarta ), Skripsi Jurusan Teknik Fisika Fakultas Teknik Universitas Gajah Mada.

[6] Lanang Ragil WTP, 2005, Kajian Perencanaan Permintaan Dan Penyediaan Energi Di Wilayah Daerah Istemewa Yogyakarta Menggunakan Perangkat Lunak Leap, Skripsi Jurusan Teknik Fisika Fakultas Teknik Universitas Gajah Mada.

[7] Novitasari Dwi, 2012, Studi Perencanaan Energi Alternatif Jangka Panjang Untuk Kabupaten Bantul Dengan Adanya Pembangkit Listrik Tenaga Hibrida ,Skripsi Jurusan Teknik Fisika Fakultas Teknik Universitas Gajah Mada

[8] Aceh Dalam Angka, 2009, BPS Aceh.

[9] Aceh Dalam Angka, 2010, BPS Aceh.

[10] Aceh Dalam Angka, 2011, BPS Aceh.

[11] Aceh Dalam Angka, 2012, BPS Aceh.

[12] Aceh Dalam Angka, 2013, BPS Aceh.

[13] Aceh Tamiang Dalam Angka, 2009, Bappeda Aceh Tamiang.

[14] Aceh Tamiang Dalam Angka, 2010, Bappeda Aceh Tamiang.

[15] Aceh Tamiang Dalam Angka, 2011, Bappeda Aceh Tamiang.

[16] Aceh Tamiang Dalam Angka, 2012, Bappeda Aceh Tamiang.

[17] Aceh Tamiang Dalam Angka, 2013, Bappeda Aceh Tamiang. 